\title{
雚 University
}

Carter, J. A. and McKenna, R. (2019) Relativism and externalism. In: Kusch, M. (ed.) The Routledge Handbook of Philosophy of Relativism. Routledge: London. ISBN 9781138484283

This is the Author Accepted Manuscript.

There may be differences between this version and the published version. You are advised to consult the publisher's version if you wish to cite from it.

https://eprints.gla.ac.uk/185653/

Deposited on: 2 May 2019

Enlighten - Research publications by members of the University of Glasgow http://eprints.gla.ac.uk 
Forthcoming in Routledge Handbook to Relativism, ed., M. Kusch

\author{
Relativism and Externalism \\ J. Adam Carter, University of Glasgow \\ Robin McKenna, University of Liverpool
}

\begin{abstract}
Internalists in epistemology think that whether one possesses epistemic statuses such as knowledge or justification depends on factors that are internal to one; externalists think that whether one possesses these statuses can depend on factors that are external to one. In this chapter we focus on the relationship between externalism and epistemic relativism. Externalism isn't straightforwardly incompatible with epistemic relativism but, as we'll see, it is very common to hold that key externalist insights block or undermine some standard arguments for epistemic relativism. Our aim in this chapter is to give a broad overview of why externalism poses a problem for standard arguments for relativism. But we also want to discuss some-admittedly less developed-ways in which some externalist ideas might actually provide support for certain forms of epistemic relativism.
\end{abstract}

\title{
1 Introduction
}

Internalists in epistemology think that whether one possesses epistemic statuses such as knowledge or justification depends on factors that are internal to one; externalists think that whether one possesses these statuses can depend on factors that are external to one. ${ }^{i}$ We can complicate this distinction in several ways. What it means for a factor to be "internal" or "external" to one is subject to debate. One might be an internalist about some epistemic statuses (e.g. justification) but not others (e.g. knowledge). For the purposes of this chapter we set these issues aside and focus on the relationship between externalism and epistemic relativism, which is, roughly, the view that epistemic statuses like justification and knowledge are themselves always relative to some non-trivial parameter, such as local norms or conventions.i 
Externalism isn't straightforwardly incompatible with epistemic relativism but, as we'll see, it is very common to hold that key externalist insights block or undermine some standard arguments for epistemic relativism. Our aim in this chapter is to give a broad overview of why externalism poses a problem for standard arguments for relativism. But we also want to discuss some ways in which externalist ideas might provide support for certain forms of epistemic relativism. We start with externalist arguments against relativism. We then move on to some ways in which externalist ideas might provide support for various forms of relativism. We finish with suggestions for future work.

\section{Externalist arguments against relativism}

Arguments for epistemic relativism often take, as a starting point, an observation that the absolutist-the epistemic relativist's opponent-can happily concede: cultures that differ across both geography and time can (and do) differ with respect to what epistemic standards they appeal to when determining whether a given belief is justified or known.

But what follows from this? A moment's reflection reveals that not all of these standards can be (absolutely) true because some are ostensibly in conflict with one another. And this observation is philosophically significant. For if one thinks that there are (absolutely) correct epistemic standards, then it is incumbent upon one-at least, insofar as one wishes to avoid scepticism-to establish that one's own epistemic standards are the right ones.

But how to do that, exactly? At this juncture, it will be helpful to consider two famous argument strategies for relativism that utilise these observations-the argument from circularity and the argument from non-neutrality. Externalism, we will then show, offers the absolutist a straightforward way to nip each of these arguments for relativism in the bud. That said, in each case we will also show why the relativist might not find the externalist counter strategy compelling. 


\subsection{Externalism as a response to the argument from circularity}

Establishing that one's own epistemic standards are the right ones can be difficult. This is especially so when one's dialectical opponent does not already accept these same standards. In fact, some argue the very attempt to demonstrate that one's own epistemic standards have a positive epistemic status (in comparison with alternative, competing standards) plays into the hands of the relativist. Michael Williams puts the idea nicely in this passage:

In determining whether a belief - any belief - is justified, we always rely, implicitly or explicitly, on an epistemic framework: some standards or procedures that separate justified from unjustified convictions. But what about the claims embodied in the framework itself: are they justified? In answering this question, we inevitably apply our own epistemic framework. So, assuming that our framework is coherent and does not undermine itself, the best we can hope for is a justification that is epistemically circular, employing our epistemic framework in support of itself. Since this procedure can be followed by anyone, whatever his epistemic framework, all such frameworks, provided they are coherent, are equally defensible (or indefensible) $(2007,3-4)$.

This reasoning - call it the argument from circularity-offers a powerful argument for epistemic relativism because it purports to show how all epistemic frameworks (and thus, all the epistemic standards that make up these frameworks) are ultimately on an equal footing. None aspires to anything more than epistemically circular justification, including the frameworks made up of the standards that we think have the most going for them, epistemically.

Consider, against the background of this puzzle, what the epistemic externalist might say. In order to sharpen things a bit, let's imagine a special case of the argument from circularity that purports to show that all standards for epistemic justification are on an equal footing. And let's look, specifically, at what the externalist about epistemic justification can say in response. As alluded to in $\S 1$, the externalist about epistemic justification denies that the 
only ${ }^{\mathrm{iii}}$ factors that matter for whether one is justified are internal factors-viz., factors that are accessible to one via reflection alone. ${ }^{\text {iv }}$

In the face of the argument from circularity (targeting epistemic justification), the externalist about justification has a two-step reply: step one involves a disambiguation and step two involves rejecting on the basis of this disambiguation a premise of the argument from circularity. The disambiguation proceeds as follows: a justification for a standard for epistemic justification can be read in multiple ways. On one reading, $X$ is a justification for epistemic standard $\mathrm{E}$ only if $\mathrm{X}$ can be adduced as a reason in favour of $\mathrm{E}$. Notice how something like this reading of "justification" lies in the background of the argument Williams sketches in the above passage when he indicates that (by the relativist's lights) "the best we can hope for is a justification that is epistemically circular".

For the externalist, by contrast, E's being justified simply doesn't require a justification in this sense. Take, for example, standard process reliabilism according to which justification is entirely a matter of reliable belief production: a belief is justified iff it is reliably produced. ${ }^{v}$ From the perspective of the reliabilist, a justification (in the sense at issue in Williams' passage) for E isn't required for $E$ to be justified. All that is required is that certain reliability facts about E obtain. And the obtaining of these facts needn't require anyone appealing to any standard in order to make them true. In slogan form: facts about justification are independent from facts about the activity of justifying; the former are not grounded in the latter.

We're in a position to see now why externalism-cum-reliabilism about justification offers the anti-relativist a way to nip the argument from circularity in the bud. For the argument from circularity trades on what happens when we try to justify our own epistemic system. And, as we've just seen, the reliabilist is in a position to challenge the argument "upstream" by simply denying the epistemological significance of justifying for justification.

We've suggested that the relativist might not find the externalist reply to the above argumentative strategy persuasive. One reason why is as follows: the relativist who subscribes to the argument from circularity might insist that even if (if externalism-cum- 
reliabilism is true) we needn't in ordinary practice justify our own epistemic standards by appealing to them in order to be justified, it is incumbent upon the reliabilist qua theorist to vindicate her beliefs as justified beliefs, and her standards as justified standards. If the reliabilist qua theorist wants to do this in an adequate way, then it is not enough that the reliabilist merely be justified in her beliefs or for that matter in her standards, but she must be able, in addition, to provide an adequate explanation for why they are justified. ${ }^{\text {vi }}$ And it is at this point that it looks as though the theorist who embraces an externalist view like reliabilism will, in the course of this kind of vindicatory project, inevitably appeal to her own standards in the course of justifying them. ${ }^{\text {vii }}$

\subsection{Externalism as a response to the argument from non-neutrality}

We will now turn to the argument from non-neutrality (e.g., Rorty 1980; Hales 2014). Perhaps the most famous example of this kind of argument strategy owes to Richard Rorty (1980), who develops the argument with reference to the historical dispute between Cardinal Bellarmine and Galileo. viii What was principally at issue between the two disputants was the matter of the truth of geocentrism, the doctrine that the Earth is the geographical centre of the Universe. As Bellarmine saw things, the doctrine was true, and he believed it to be true on the basis of Scripture. Galileo, by contrast, concluded that the doctrine was false. His reasoning was that, on the basis of telescopic evidence, he could observe moons orbiting Jupiter, a phenomenon that is better explained by the heliocentric model than the geocentric model. Moreover, Galileo took the evidence he received from the telescope to not only favour the heliocentric model over the geocentric model, but also to indicate that Scripture was not a reliable source of evidence about the movement of celestial bodies. Bellarmine, for his part, took the authority of Scripture to indicate that Galileo's telescopic evidence must be mistaken.

As Rorty saw it, the dialectical situation we find in this kind of dispute-viz., where there is both a (i) first-order disagreement about what is so, and (ii) an intractable kind of metadisagreement about what even counts as suitable evidence that would bear on whether something is so-is one we should diagnose along relativist lines: Galileo is right according 
to scientific standards, Bellarmine is right according to Scriptural standards, and there is no further sense in which things here can be adjudicated. ${ }^{\text {ix }}$

There are a variety of ways one might attempt to respond to this kind of argument from an anti-relativistic perspective. ${ }^{\mathrm{x}}$ But perhaps the most straightforward strategy belongs to the epistemic externalist. For if the externalist (e.g., the reliabilist) is correct, then a central premise of Rorty's argument from non-neutrality is simply undercut. Rorty's diagnosis appeals implicitly to the idea (which he does not explicitly defend) that there can be a (nonrelative) resolution of the dispute concerning the existence of the moons only if there is some kind of suitably neutral, shared epistemic standard that Bellarmine and Galileo could appeal to in order to adjudicate their dispute (something Rorty thinks there is not). ${ }^{\mathrm{i}}$

The externalist is now in a position to respond: whether or not Bellarmine or Galileo is epistemically justified in believing either the first-order celestial claim at issue or the second-order claim about which kind of evidence is relevant to adjudicating the first-order issue, is itself entirely orthogonal to the matter of whether the two parties can find any common ground. If either side in fact has reliably formed beliefs, then these beliefs are justified, otherwise not. A broader point can be gleaned here: to the extent that considerations to do with "deep disagreements" (such as the Bellarmine/Galileo dispute) are taken to be evidence for epistemic relativism, the externalist has a principled reason to disagree. In slogan form, the factors that make you justified will continue to make you justified even when other people think they don't (and even if you are unable to rationally persuade them by their own lights that they do).

Does the relativist sympathetic to Rorty's non-neutrality argument have a reply here? It turns out they do, though it will ultimately be a dangerous one to rely upon. The first step in the reply is to appeal to the plausibility of a position known in the peer disagreement literature as conciliationism. ${ }^{\mathrm{xii}}$ According to conciliationism, if you find that someone who you previously regarded as your epistemic peer disagrees with you about $p$, then you are rationally required to downgrade your confidence that $p$ is true. To the extent that conciliationism offers a plausible way to think about the epistemic significance of disagreement given the absolutist assumption that at most one party to a disagreement is 
right, the relativist is in a position to 'revive' the pro-relativist import of deep disagreements against the externalist.

Here is the idea, in outline: Given the prevalence of disagreement about philosophical views, including views about epistemic standards (such as the kind of view the externalist/reliabilist is advancing), conciliationism seems to lead to widespread agnosticism about epistemic standards if absolutism is assumed. Granted, the absolutist can avoid the agnostic result by rejecting conciliationism and accepting that each party to the disagreement can rationally hold their ground. In this way, widespread disagreement about epistemic standards (something the externalist should be willing to countenance) wouldn't imply agnosticism about those very standards. However, it follows from this view-nonconciliationism - that disagreeing with someone you think is just as likely to be right as you isn't something that will be epistemically significant for you even when you both think only one of you can be right. Forced with a choice between (i) the hard-line non-conciliationist option, (ii) wholesale agnosticism about epistemic standards; and (iii) the denial that at most one party to a dispute can be right, the relativist suggests the third option should look the most attractive to the (non-sceptical) externalist. For by denying that at most one party can be right, the threat of scepticism about epistemic standards is off the table for the externalist who grants that at least some epistemic peers deny externalism.

We flagged that the above reply is a potentially dangerous one for the relativist to rely on. Here is why. The argument relies on two points the proponent of externalism is in a position to contest. Firstly, the externalist might claim that, if they encountered someone who they previously regarded as an epistemic peer, but who denied externalism, they would rightly no longer view that individual as an epistemic peer. Secondly, even if the previous response is not a viable one, the argument goes through only if relativism should be thought more attractive to the externalist than should the package of absolutism, conciliationism and scepticism, or the package of absolutism and non-conciliationism. And it's far from clear that this will be the case. 


\section{Externalist arguments for relativism}

As we have just seen, externalist views in epistemology are often taken to undercut support for relativism. But one can also argue that externalist views provide support for certain forms of relativism. In this section we will review some of these arguments. Throughout the focus will be on a particular externalist view: (process) reliabilism.

\subsection{Doxastic vs. propositional justification}

Put roughly, some subject $\mathrm{S}^{\prime} \mathrm{s}$ belief that $\mathrm{p}$ is propositionally justified iff $\mathrm{S}$ has good reasons for believing that $p$. But S may be aware of good reasons for believing $p$ yet not believe $p$ on the basis of those reasons (or S may not believe $\mathrm{p}$ at all). Imagine Catriona is aware of good reasons for believing that it will rain later (she has read a reliable forecast), but she doesn't believe that it will rain on the basis of the forecast, but rather on the basis of superstition ("red sky at dawn, shepherd's warning"). Catriona's belief is propositionally justified, but it isn't doxastically justified, because it isn't believed on the basis of good reasons. The problem with Catriona's belief is that it wasn't formed in the right sort of way.

In his classic 1979 paper "What is Justified Belief?", Alvin Goldman proposed a reliabilist theory of justification on which (put roughly) $S^{\prime} s$ belief that $p$ is (doxastically) justified iff it is formed in the right sort of way, and a belief is formed in the right sort of way iff it is produced by a reliable process. Goldman's theory treats doxastic justification (in Goldman's terms, "ex post justification") as the primary notion, and defines propositional justification (which Goldman calls "ex ante justification") in terms of it. S's belief that $p$ is doxastically justified iff it is produced by a reliable process, and then it is propositionally justified for $S$ at some time $t$ iff $S^{\prime} s$ total cognitive state at $t$ is such that $S$ could come to be doxastically justified in believing that $p$. In our earlier example, Catriona's belief that it will rain is not doxastically justified (she formed it on the basis of superstition), but it is propositionally justified, because if she were to believe on the basis of the forecast, she would be doxastically justified. 
While it isn't often remarked on, this view involves an interesting, albeit mild, form of relativism about propositional justification. xiii On Goldman's theory, whether S has propositional justification to believe $p$ is going to depend on a combination of their total cognitive state and what propositions they could come to be doxastically justified in believing. Two individuals could therefore be aware of precisely the same evidence, ${ }^{\text {xiv }}$ yet $p$ might be (propositionally) justified for one but not for the other. Imagine Morven, who is just like Catriona except she is psychologically incapable of trusting weather forecasts because of her deep distrust of the meteorological establishment. As a result, Morven could not become doxastically justified in believing that it will rain, because she is psychologically incapable of forming this belief in the right way. Thus, for Goldman's theory, whether $\mathrm{S}$ has propositional justification is relative not just to their total cognitive state, but also the intricacies of their psychological makeup. Goldman's theory is therefore tantamount to a form of psychologism about justification. ${ }^{x v}$

\subsection{Reliability vs. beliefs about reliability}

There is another respect in which "What is Justified Belief?" leaves the door open for a form of relativism. There may be a difference between which processes count (by the lights of our best science) as reliable and which processes are actually reliable. We don't think that wishful thinking is reliable. But imagine that, unbeknownst to us, there is a benevolent demon who has recently decided for reasons of their own to make it so that beliefs formed through wishful thinking are almost always true. In such a scenario, wishful thinking would be a reliable way of forming beliefs, but Goldman doesn't think this would mean that beliefs formed through wishful thinking are justified:

What we really want is an explanation of why we count, or would count, certain beliefs as justified and others as unjustified. Such an explanation must refer to our beliefs about reliability, not to the actual facts. The reason we count beliefs as justified is that they are formed by what we believe to be reliable belief-forming processes. Our beliefs about which belief-forming processes are reliable may be erroneous, but that does not affect the adequacy of the explanation. Since we 
believe that wishful thinking is an unreliable belief-forming process, we regard beliefs formed by wishful thinking as unjustified. What matters, then, is what we believe about wishful thinking, not what is true (in the long run) about wishful thinking (Goldman 1979, 101)

For Goldman, what confers justification on a given belief is that it is produced by a process that we believe to be reliable. While this doesn't in itself provide support for any form of relativism, it does if we add the premise that different communities may (justifiably?) count different processes as reliable. The strength of the relativism that results will depend on the strength of this premise. The weakest version would just state that, at different points in human history, we have counted different processes as reliable (which is not to say that we haven't counted a core set of processes as reliable at all points in human history). On this version, we might get interesting results in the debate between Bellarmine and Galileo: maybe in Bellarmine's time it was justifiable to regard Scripture as reliable. A stronger version would state that different present-day communities count different processes as reliable (which again is not to say that all communities don't count a core set of processes as reliable). Either way, we get a sort of relativity of justification to what counts (and doesn't count) as reliable.

\subsection{The generality problem}

One central problem for reliabilism is the so-called "generality problem". We will finish this section with Robert Brandom's (1998) argument that "solving" the generality problem requires acknowledging a sort of relativity.

Brandom's objection targets the claim that reliabilism is a "naturalistic" epistemology. But Brandom's version of the generality problem is meant to show that reliabilism is less naturalistic than it seems. The reliabilist holds that whether a token belief is justified depends on whether the cognitive process that produced it was sufficiently likely to produce a true belief. Consider Alvin. Alvin is looking at a barn in normal conditions and accordingly forms the belief that there's a barn in front of him. Alvin is located in fake barn county, in 
which there are far more fake barns than real barns. But fake barn county is located in real barn state, in which there are far more real barns than fakes, and real barn county is located in fake barn country, in which there are far more fake barns than real barns. Here's a helpful diagram:

Figure 1: Alvin's predicament

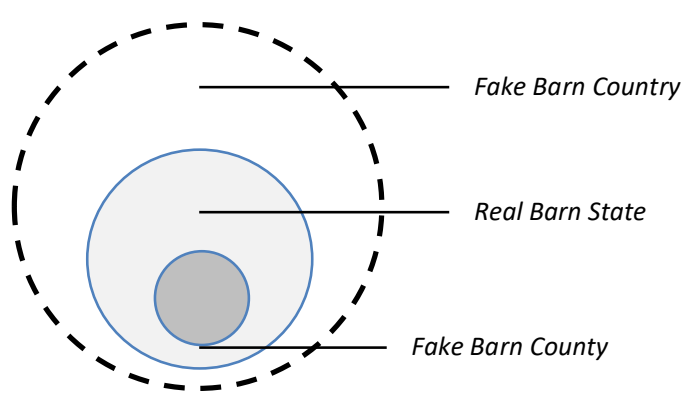

Is Alvin's belief (that there's a barn in front of him) reliable? Brandom's point is that it depends on which reference class we evaluate for reliability relative to. If we evaluate relative to fake barn county or country, it is unreliable (if he had been standing in front of a fake, he would still have believed it was a barn). But, if we evaluate relative to real barn state, it is reliable. What, then, are we to say then about Alvin? Brandom says:

Which is the correct reference class? Is [Alvin] an objectively reliable identifier of barns or not? I submit that the facts as described do not determine an answer. Relative to each reference class there is a clear answer, but nothing in the way the world is privileges one of those reference classes, and hence picks out one of those answers $(1998,386)$.

Brandom concludes that reliability can only be specified relative to a reference class, and there is nothing "in the world" that determines a single reference class as privileged. Thus, there is no simple fact of the matter about whether token beliefs like Alvin's are reliable. Relative to some choices of reference class (e.g. real barn state), they are; relative to others (e.g. fake barn county or country), they aren't.

The crucial thing for our purposes is that Brandom does not conclude that reliabilism should be rejected. Rather he concludes that reliabilism cannot live up to its naturalistic credentials 
because justification cannot be purely a function of the psychological processes that produce or preserve belief. Whether a belief is justified depends on whether it is reliable for the purposes at hand. As Michael Williams puts the point:

Reliability itself becomes reliability for particular purposes. This is particularly evident in sophisticated forms of inquiry. In particle physics, the standard for "detecting" a particle has moved from three to five sigma, the standard in effect when the discovery of the Higgs boson was announced ... This is a very high standard, but a reasonable one given that "discoveries" at three sigma - itself a high standard - have sometimes turned out to be statistical blips. Reliability is a norm that we are not only responsible to but, in certain applications, responsible for (Williams 2015, 267-68).

If reliability is a norm that we are responsible for then it may be that what we will require for reliability will vary from situation to situation (or community to community). Whether the form of relativism that results is benign or not is going to depend on how much (and what sort) of variation we are willing to counter. Those who push this point (like Brandom and Williams) tend to play down the degree of variation, and so the relativistic consequences. But Brandom's reflections on the generality problem leave the door open for radical forms of relativism, on which different communities are free to decide on the level of reliability they require.

\section{Conclusions}

We will finish by pointing to avenues for future research. Starting with externalist arguments against relativism, a recurring theme is that, while externalism promises to undercut some central arguments for relativism, the relativist has some moves at their disposal. In the case of the argument from circularity, she can insist that it is incumbent upon the reliabilist qua theorist to vindicate her beliefs as justified beliefs, and her standards as justified standards. The reliabilist may face serious difficulties in doing so, at least if the literature on the "bootstrapping" and "easy knowledge" problems is anything to go by. ${ }^{\text {xvi }}$ In the case of the argument from non-neutrality, the viability of a relativist response 
to the reliabilist depends on the viability of conciliationism as a response to philosophical disagreement. So the outcome of the relativist's "encounter" with the reliabilist is going to depend on the outcome of some central epistemological debates. This suggests that relativism (and the relativist) can hardly be regarded as being off the epistemological table.

Turning to ways in which externalism might provide support for (certain forms of) relativism, we saw that externalist ideas do arguably provide support for some forms of relativism. The key question here is whether these forms of relativism are what the absolutist is really concerned to deny. We can of course define "epistemic relativism" in all sorts of ways, but the term is generally seen as denoting a view that is threatening to mainstream epistemology. It is an open question whether any of the forms of relativism discussed constitute such a threat. Perhaps the most interesting idea in this respect is that "we" get to determine what "reliable" amounts to. If the view is just that there is some vagueness in the idea of a reliable belief-forming process, then it is perhaps not so interesting. If the view is that the status of a belief forming process as "reliable" is subject to social negotiation, then perhaps it represents the sort of threat to epistemological orthodoxy that is worthy of the name "epistemic relativism".

\section{References}

Baghramian, Maria, and J. Adam Carter. 2015. 'Relativism'. In The Stanford Encyclopaedia of Philosophy (Fall 2015 edition), edited by Edward N. Zalta.

$\mathrm{URL}=\langle$ http://plato.stanford.edu/entries/relativism/>

Boghossian, Paul. 2006. Fear of Knowledge: Against Relativism and Constructivism. Oxford: Oxford University Press.

Brandom, Robert. 1998. "Insights and Blindspots of Reliabilism." The Monist 81 (3): 371-92.

Carter, J. Adam. 2016. Metaepistemology and Relativism. London: Palgrave Macmillan. . forthcoming. 'Archimedean Metanorms'. Topoi. doi: 10.1007/s11245-018-9586-9

Cohen, Stewart. 2002. "Basic Knowledge and the Problem of Easy Knowledge." Philosophy and Phenomenological Research 65 (2): 309-29.

Conee, Earl, and Richard Feldman. 2004. Evidentialism: Essays in Epistemology. New York: Oxford University Press.

Frances, Bryan, and Matheson, Jonathan. 2018. 'Disagreement'. In The Stanford 
Encyclopedia of Philosophy (Spring 2018 Edition), edited by Edward N. Zalta.

URL $=\langle$ https://plato.stanford.edu/archives/spr2018/entries/disagreement/>.

Goldman, Alvin. 1976. "Discrimination and Perceptual Knowledge." Journal of Philosophy 73: 771-91.

. 1979. "What Is Justified Belief?" In Justification and Knowledge, edited by George Pappas, 89-104. Dordrecht: Springer.

. 1999. "A Priori Warrant and Naturalistic Epistemology." Philosophical Perspectives 13: 1-28. https://doi.org/10.2307/2676094.

Hales, Steven D. 2014. 'Motivations for Relativism as a Solution to Disagreements'.

Philosophy 89 (1): 63-82.

Kornblith, Hilary. ms. 'Naturalism, Psychologism, Relativism'.

Kusch, Martin. 2016. "Psychologism." Edited by Edward N. Zalta. The Stanford Encyclopedia of Philosophy (Winter 2016 Edition).

$\mathrm{URL}=<$ https://plato.stanford.edu/archives/win2015/entries/psychologism/>.

Pappas, George. 2017. 'Internalist vs. Externalist Conceptions of Epistemic Justification'. In The Stanford Encyclopedia of Philosophy (Fall 2017 Edition), edited by Edward N. Zalta (ed.).

URL $=<$ https://plato.stanford.edu/archives/fall2017/entries/justep-intext/>

Rorty, Richard. 1980. Philosophy and the Mirror of Nature. Princeton, N.J.: Princeton University Press.

Siegel, Harvey. 2011. 'Epistemological Relativism: Arguments Pro and Con'. In A Companion to Relativism, edited by Steven Hales, 199-218. Wiley Online Library.

Sosa, Ernest. 1997. 'Reflective Knowledge in the Best Circles'. The Journal of Philosophy 94 (8): 410-430.

. 2011. Reflective Knowledge: Apt Belief and Reflective Knowledge, Volume II. Oxford: Oxford University Press.

Stroud, Barry. 2008. 'Perceptual Knowledge and Epistemological Satisfaction'. In Ernest Sosa and His Critics, 165-73. John Wiley \& Sons, Ltd.

Williams, Michael. 2007. 'Why (Wittgensteinian) Contextualism Is Not Relativism'. Episteme 4 (1): 93-114. . 2015. “What's so Special about Human Knowledge?" Episteme 12 (2): 249-68. 


\footnotetext{
' For an overview of the internalism/externalism distinction see Pappas (2017).

ii See Baghramian and Carter (2015) for a comprehensive discussion. See also Carter (2016, Ch. 2).

iii This is not to say that the only things that matter for whether a belief is justified are things beyond what is reflectively accessible to one.

iv This is one common way to capture the view. But one might also be an externalist about epistemic justification because one denies a different version of epistemic internalism called "mentalism" (see Conee and Feldman 2004). Mentalist interests hold that what matters for epistemic justification are factors internal to one's mental life; captured as a supervenience thesis, the claim is that justification supervenes exclusively on internal factors, which are understood as mental states. An externalist who denies mentalist internalism is best understood not as denying that what matters for justification must be accessible by reflection, but rather, as denying that (in short), necessarily, mental duplicates are justificational duplicates.

$\checkmark$ The locus classicus is Goldman (1979).

vi For helpful discussion on this point, see Stroud (2008) and Sosa (2011).

vii $A$ response to this strand of argument is developed in detail in Sosa (1997).

viii For an influential presentation and criticism of this argument, see Boghossian (2006).

ix For a more recent defence of this argumentative strategy, see Hales (2014). For critical discussion of this argument strategy, see Siegel (2011) and Carter (2016, Ch. 4; forthcoming).

${ }^{x}$ For one thing, it is unclear that the reasoning here favours relativism over scepticism. See Carter (2016, Ch. 4).

xi See Siegel (2011) for an attribution of this implicit premise to Rorty.

xii For an overview of the epistemology of disagreement see Frances and Matheson (2018).

xiii What follows is based on Kornblith (ms.), though his discussion is more sophisticated than what we say here.

xiv Modulo views on which it is impossible for two individuals to be aware of precisely the same evidence.

${ }^{x v}$ For more on psychologism see Kusch (2015).

xvi For both problems see Cohen (2002).
} 